\title{
Das coincidências na pesquisa e na produção antropológicas
}

\section{Sílvıo Coelho dos Santos}

\begin{abstract}
A Antropologia no Brasıl teve grande incremento a partır da im- Lplantação dos programas de pós-graduação, nos finais dos anos sessenta do século passado Os campos tradicıonaıs da pesquisa etnografıca, focalızando povos indıgenas e populações ruraıs e urbanas, se diversificaram rapıdamente Minha trajetorıa como pesquisador incluı pruncıpalmente unvestıgações com indıgenas no Sul do Brasıl, abordando temátıcas como contato interétnıco, educação, dureıto de munorıas e consequências sociaıs de projetos de desenvolvımento Nesta comunıcação, quero destacar que alguns dos projetos que desenvolv foram minciados em circunstâncias não previstas inıcialmente As decısões que tive de tomar entraram mais no terreno das coincidências do que no cenano das escolhas programadas Foram, portanto, fruto de circunstâncias Quero exemplificar com duas temátıcas que trabalheı intensivamente e que não foram escolhas realizadas interramente sob o meu controle, como pesquisador Trata-se, parodıando Norberto Bobbıo, das mutas coincidênclas, azares e incertezas que regem a nossa vida, e que nos fizeram chegar até aqui enquanto profissionais da Antropologia

Em 1972, obtıve o grau de doutor na Unıversıdade de São Paulo com a tese 'Índıos e Brancos no Sul do Brasıl - a dramatıca experıêncıa dos Xokleng" Tratava-se de um longo estudo de "frıcção unteretnıca",
\end{abstract}


focalızando a trajetónıa dos indígenas Xokleng, tıadıcıonaıs habıtantes do Sul do Brasıl, em seu relacionamento com os brancos O contexto da violêncıa pratıcada pelas frentes de expansão, que se incrementou com a ımıgração europeıa nos meados do século XIX, foı amplamente ressaltada neste trabalho que, diga-se, for produzıdo no auge do autoritarısmo umposto pela ditadura militar (1964- 84) A defesa da tese, as críticas da banca e depois do publico, pois a obra fol publicada em 1973, levaram-me a pensar num novo trabalho voltado para a análise dos grupos de exterminıo dos indígenas, os bugreuros, que, em regra, eram formados por brasıleiros mestıços, denomunados caboclos Esse mesmo contıngente deu o suporte ınıcıal as empresas de colonızação e aos colonos, cnquanto força de trabalho e como fonte de informação para o necessárıo domínı do meı̀ ambıente Aproveitarıa, para tanto, boa parte do materıal biblıográfico e de campo que havia fundamentado munha pesquisa anterior Os obstaculos, entretanto, para concretizar esse projeto foram muitos, em particular os financeiros Depois de meses de tentativas frustradas para obter financiamento, nada estava resolvido Por meios transversos, tive notícia de que a Fundação Ford estava abrundo um processo seletıvo para projetos na area de educação Como eu tinha tıdo alguma experıência como al fabetızador de adultos e como professor de curso "prımárıo", resolvı propor um pequeno projeto de levantamento da situação das escolas que funcionavam nas áreas indígenas, no Sul do Brasıl Com surpresa, meses depois, tome conhecimento que a proposta fora aprovada e que os recursos financerros para a sua execução estavam garantıdos Fol com esse projeto que logi ei realızar um survey nas diferentes areas indígenas do sul do país O projeto inicial for bastante ampliado As polítıcas pratıcadas pelo antıgo Servıço de Proteção aos Indıos (SPI) e, depois de 1967, pela Fundação Nacional do Índı (Funal) em relação aos índıos foram melhor avaliadas Os recursos da fotografia foram utılızados para demonstrar a degradação das ıeservas indígenas, e pude oportunizar inıcıação em campo de diversos estudantes Da proposta inıcial, resultou o livro Educação e Soctedades Trıbais (Porto Alegre, Editora Movımento, 1975) Deı especial atenção nesse Iivro (1) as relações de subordınação dos ındígenas a socıedade regıonal, (i1) 
a falacia dos projetos econômicos implantados pela Funaı em terras ındígenas (ul) as possıbılıdades e lımites da educação Alem dısso, realızeı uma avalıação da únıca experıêncıa de ensıno bılıngue que se desenvolvia na área abrangıda pela pesquısa, por ınıcıatıva de uma instıtuıção relıgıosa Fız uncluur, aunda, um apêndıce onde focalızava os indios que viviam fora de suas aldeıas, na perıferıa das cıdades e, ou, servindo como mão de obıa em propıedades ruraus Dados dessa pesquisa serviram, ainda, para fundamentar dezenas de palestras e debates em tomo da tematıca da educação mdigena Numa época em que a educação não era um tema explorado pela Antropologıa, este lıvro acabou pıoneıro Ao mesmo tempo, me ımpôs a temátıca indıgena como recorrente Mas não só, nos anos seguintes a produção da obra o Homem Indio sobrevivente do Sul (Porto Alegre, Garatuja, 1978), que falareı no ıtem segumte, teve por base a documentação fotográfıca e os dados de campo obtıdos nessa pesquisa

\section{Aproximação com os advogados}

Logo depois da conclusão de meu doutorado, a area de ensino jurídıco da mınha Unıversıdade começou a organızar um curso de mestrado Num certo momento, fur convidado para colaborar com esse projeto devido ao fato, creio, do numero insuficiente de professores doutores na instıtuıção Ao aceitar o convite para lecionar as discıplınas "Metodologia da Pesquisa" e "Antropologıa do Desenvolvimento", o que fız por três anos, pretendı colaborar com a ınıcıatıva e, ao mesmo tempo, vivenciar uma rara oportunidade de atuar no primeiro curso da área de humanıdades da Unıversıdade Nesse momento, a possıbılıdade de se implantar um curso de pos graduação em Antropologıa aında estava distante Essa vivêncıa com area jurıdıca permıtıu saber que a temátıca indígena não integrava o currículo do curso de graduação, nem tampouco era atraente para os alunos de pós-graduação Alguns estudantes chegaram a me questıonar, informalmente, da relevâncıa de alguem dedicar seu tempo a essa temátıca Esse desconhecimento aos poucos for me colocando dıante da falta de comunıcação entre as diferentes areas do conhecımento na Unıversıdade Deıxeı de atuar no Programa de Pos-graduação em Direıto para organızar e coordenar um curso especialızação de Cıêncıas Socıaıs com opções em Antropologıa 
Socıal e Socıologıa, que foı ımplantado na UFSC, em 1976 As relações com os profıssionais do Direito, entretanto não foram abandonadas Gradatıvamente, tomel consclência de que era necessarı uma aproxımação crescente entre antropologos e advogados, com vistas a defesa dos direitos dos povos indígenas Ao preparar os orıgunais do livro $O$ Homem indio Sobrevivente do Sul, já referıdo, utılızeı como epígrafe os artıgos da Declaração Unıversal dos Direitos Humanos, aprovada pela Assembleıa Geral das Nações Unıdas, ein 1948, com o objetıvo explıcıto de ressaltar os direitos das munorias Esse livro fol consequência do semınárıo O indıo sobrevivente do Sul", organizado em Porto Alegre, no ano antenor, por diversas entıdades cıvıs, e que se realızou na Assembleıa Legislativa daquela cidade For a primena vez que, durante o regime milutar, um numero expressivo de antropologos, advogados relıgıosos, indıgenıstas e lıderanças ındıgenas e cıvıs se ı eunıu para explıcıtar e defender os direitos dos povos minoritarıos Desse semınárıo, resultou a fundação da Assocıação Nacıonal de Apoıo ao Índıo (ANAI), entıdade para a qual doeı os dureitos autorais dos livro acima referıdo Logo em seguida, aunda como efeito positivo desse encontro, surgıram as Pró-Indıo de São Paulo c do Rıo de Janeıro Na luta pela afırmação dos dureıtos dos povos undıgenas, em 1980, organızamos uma reunião entre antropólogos e advogados, untıtulada "O Índıo Perante o Direito" Esse encontro teve o apoio da Cultural Survival Inc, através do professor Davıd Maybury-Lewıs, da Harvard Unıversıty (USA) O professor Maybury Lewıs conseguıu uma dotação financeura para viabilızar a reunião e logrou publıcar uma versão compacta em inglês dos documentos conclusivos (Occasional Paper 5, Cultural Survival, Cambrıdge, USA 1981 Da mesma maneıra, a Revısta Ciêncıa e Cultura, da Sociedade Brasıleıra para o Progresso da Ciêncıa -SBPC, deu dıvulgação a essa versão compactada a sob o titulo Os Indıos Perante o Diretto (1981, 33 (2) 161 -166) A repercussão desse encontro fol expressiva A SBPC em sua $33^{\text {a }}$ Reunão Anual, realızada em junho de 1981, abrigou uma mesa redonda sobre o mesmo tema e a Pró-Índıo São Paulo, em parcerıa com a Assocıação Brasıleıra de Antropologıa (ABA), promoveu um encontro denomunado "O Indıo e os Direitos Historicos" Ao final do encontro em Florianópolıs foram aprovados os seguintes 
documentos 1 sobre terras indıgenas, 2 sobre a tutela e a integração dos povos indígenas 3 sobre a construção de barragens e os direıtos dos povos indigenas, 4 sobre parques nacionais em areas de parques indigenas, 5 sobre o trabalho dos antropologos e a Funal, 6 sobre o projeto Rondon e as áreas ındıgenas, 7 proposıções e recomendações A Editora da UFSC publicou a coletânea dos trabalhos apresentados, o rol de partıcıpantes (23 antropólogos, 10 advogados e 11 convidados especiais), e os documentos conclusivos no livro $O$ Indio Perante 0 Direito-ensaios que fol organizado por mim, em 1982 Em outubro de 1983, logramos efetıvar, com o apoı do CNPq, uma segunda reunıão, agora denommada "Sociedades Indigenas e o Direito - uma questão de direıtos humanos" Partıciparam 21 antropologos, 9 advogados e 7 observadores especials Os textos das comunicações apresentadas, os documentos finais dos grupos de trabalho e as moções aprovadas foram reunidas no livro Sociedades Indigenas e o Direttos - uma questão de direntos humanos, que teve como organızadores Sílvı Coelho dos Santos, Dennıs Wernner, Neusa Bloemer e Anelıese Nacke A publıcação fol feıta pela Edıtora da UFSC, em coedıção com o CNPq, em 1985 Destaca-se, na apresentação, que a reunião objetıvou a discussão de dols problemas fundamentaıs "o prumerro, refere-se a realıdade plurıetnıca e multıssocietarıa do Brasıl, em confronto com a ıdeologıa tradıcıonal, porem vigente de Estado unınacional, consagrada na Constıtuıção" $O$ segundo remete a formulação de estrategias que permitam cada vez mais aos integrantes das sociedades indigenas terem assegurada a assistência juridıca, com vistas a garantır seus dureitos junto a sociedade nacional envolvente" Com certeza, essas duas reuniões foram altamente estrategıcas para fundamentar as discussões que se sucederam nos anos seguntes relacıonadas a elaboração de uma nova Constıtuıção fato que se concretızou em 1988 Nessa nova Carta Magna, o capítulo 'Dos índıos" assegurou aos indígenas direitos relativos ao reconhecımento pelo estado bıasıleiro da sua exıstência enquanto povos garantındo-lhes sua perpetuação bıológıca e cultural, assıstêncıa a educação e a saude, e direito às terras de ocupação tradıcıonal Um outro lıvro de minha autorla Povos Indigenas e a Constıtuinte, (Porto Alegre, Movimento/ Edıtora da UFSC, 1989), sıntetıza os avanços que 
se pretendia alcançar no relacionamento dos povos indígenas com o Estado incluindo outras reuniões e encontros que ocorreram no País sobre essa temática Certamente, os legısladores não incorporaram todas as reıvındıcações na Carta Magna, porém, ha que se reconhecer que consıgnaram alguns avanços Com a promulgação da Constıtuıção Federal de 1988, onde foram delıneadas novas relações entre os povos ındıgenas e o Estado brasıleiro, o tema dos dıreitos dos indıos passou a ser tratado por várias organızações governamentaıs e não governamentais A Assocıação Brasıleıra de Antropologıa ( $\mathrm{ABA}$ ) teve várıas ınıciatıvas para aprofundar as questões relacıonadas a essa temátıca, sempre contando com a partıcıpação de advogados De munha parte, contunueı partıcıpando de debates, realuzando palestras e produzundo textos sobre a questão dos direıtos dos povos minorıtárıos, em partıcular os ındıos O tema contınua, assım, no meu dıa a dıa Poderıa dızer, a esta altura, que o que fol produto de sıtuações não previstas virou tema permanente de meu cotıdıano Concluındo, vou apenas citar Grande sertão veredas, de Gumarães Rosa (2), certamente um dos maıres expoentes da literatura brasileira, destacando o diálogo em que Riobaldo, seu personagem, diz 'Eu atravesso as colsas - e no meıo da travessıa não vejo' - so estava era entretıdo na ıdeıa dos lugares de saída e chegada Assaz o senhor sabe a gente quer passar num rio a nado, e passa Mas val dar na outrabanda é num ponto muito ma1s embaixo, bem dıverso do que prımeiro se pensou"

\section{Notas}

(*) Comunıcação apresentada na mesa redonda Trajectorıas y Diversıdadad - Ias estrategıas em investıgacion etnografıca durante a realızação da VI Reunião de Antropologos do Mercosul Montevideo Urugual de 16 a 18 de novembro de 2005

\section{Referências}

BOBBIO, Norberto O tempo da memorna de senectude e outros escritos auto bıograficos Rıo de Janeiro Campus 1997

CUNHA Manuela Carneuro da Os direntos do indıo ensaros e documentos São Paulo Brasilense 1987 
NUCLEO DE DIREITOS INDIGENAS (NDI) Textos classicos sobre o Diretto e os povos indigenas Curitiba Jurua NDI, 1992

REPUBLICA FEDERATIVA DO BRASIL Nova Constttuţ̧ão do Brasıl Rıo de Janeiro Aurverde 1988

ROSA Gumarães Grande sertão veredas Ruo de Janeiro J Olympıo 1965

SANTOS Silvıo Coelho dos Educação e soctedades trıbas Porto Alegre Movı mento 1975

SANTOS Silvio Coelho dos O homem indio sobrevivente do Sul Porto Alegre Garatuja, 1978

SANTOS Silvio Coelho dos (Org) O indio perante o Diretto Florianopolis Ed da UFSC 1983

SANTOS Sílvio Coelho dos Povos indigenas e a Constituınte Porto Alegre Mo vimento Flonanopolis Ed da UFSC 1989

SANTOS, Silvio Coelho dos et al (Org) Sociedades indigenas e o Diretto uma questão de dıreitos humanos Florianopolıs Ed da UFSC, 1985 